\title{
Development of failure evaluation method for BWR Lower head in severe accident; - Creep damage evaluation based on thermal-hydraulics and structural analyses -
}

\author{
Jinya KATSUYAMA*, Yoshihito YAMAGUCHI**, Yoshiyuki NEMOTO*, \\ Yoshiyuki KAJI* and Hiroyuki YOSHIDA* \\ * Nuclear Science and Engineering Center, Japan Atomic Energy Agency (JAEA) \\ Shirakata 2-4, Tokai, Ibaraki, 319-1195 Japan \\ E-mail: katsuyama.jinya@jaea.go.jp \\ ** Nuclear Safety Research Center, JAEA \\ Shirakata 2-4, Tokai, Ibaraki, 319-1195 Japan
}

Received 30 November 2015

\begin{abstract}
In existing severe accident codes such as MELCOR and THALES2, rupture of reactor pressure vessel (RPV) by relocated molten core is judged using simple models such as temperature and/or stress criteria. However, it is difficult to assess rupture behavior of the lower head of RPV in boiling-water-type nuclear power plants due to severe accident like Fukushima Daiichi. One reason is that boiling water reactors (BWRs) have geometrically complicated structure with a lot of penetrations. Another one is that BWR lower head is composed of various types of materials of RPV, weld-overlay cladding, control rod guide tubes, stub tubes, welds, etc. Therefore, we have been developing an analysis method to predict time and location of RPV lower head rupture of BWRs considering creep damage mechanisms based on coupled analysis of three-dimensional thermal-hydraulics (TH) and thermal-elastic-plastic-creep analyses. The detailed three-dimensional model of RPV lower head with control rod guide tubes, stub tubes, and welds are constructed. TH analysis is performed to obtain three-dimensional temperature distribution in relocated debris. Using $\mathrm{TH}$ analysis results, structural analysis is carried out to evaluate creep damage distributions using four types of damage criterions of "considere", strain, Kachanov, and Larson-Miller-parameter (LMP) criteria. Creep damage evaluation based on Kachanov and LMP models is made by using experimentally determined parameters. From comparison of damage criterions, it is shown that failure regions of BWR lower head are only penetrations under simulated conditions, although there is a large difference in failure time.
\end{abstract}

Key words : Fukushima Daiichi, Finite element analysis, Coupled analysis, Thermal-hydraulics analysis, Elastic-plastic-creep analysis, Creep failure evaluation

\section{Introduction}

After the Fukushima Daiichi (1F) nuclear power plant (NPP) accident due to the Pacific coast of Tohoku earthquake and Tsunami in March, 2011, Japan Atomic Energy Agency (JAEA) has been conducting various research activities for the early completion of the decommissioning of NPPs. Before the $1 \mathrm{~F}$ accident, several researches regarding phenomena inside the reactor and failure behavior of the reactor due to severe accidents had been actively conducted in reaction to the Three Mile Island accident in 1979 (Onizawa, 1993), (Humphphries, 2002), (Tran, 2010), (Villanueva, 2010). However, it is difficult to assess rupture behavior of the lower head of RPV in boiling-water-type NPPs like 1F due to severe accident. One reason is that boiling water reactors (BWRs) have geometrically complicated structure including a lot of penetrations with large diameter. Another one is that BWR lower head is composed of various types of materials of RPV, weld-overlay cladding, control rod guide tubes, stub tubes, welds, etc. Therefore, we have been developing an analysis method to predict time and location of rupture for RPV lower head of BWRs considering creep damage mechanisms based on three-dimensional thermal-hydraulics (TH) and thermal-elastic-plastic-creep analyses. Such method may contribute to assess progress of severe accident and to estimate situation of inside of the reactors of NPPs, and to improve existing severe accident codes, e.g. MELCOR and THALES2, which judgment methods for RPV rupture are simple such as temperature and/or stress criteria. 
In this study, we develop finite element model of RPV lower head including penetrations, welds and core internals, and prepare several creep damage failure models to predict time and location of RPV lower head rupture. Structural response and failure behavior due to heating by molten core is evaluated by coupled analysis of TH and structural analyses. The analysis codes used for the coupled analysis are FINAS/CFD (ITOCHU Techno-Solutions Corporation, 2013) and FINAS/STAR (ITOCHU Techno-Solutions Corporation, 2013). The behavior of molten core at the RPV lower head is evaluated by TH analysis. Using temperature at the surface of RPV obtained from TH analysis, structural analysis based on elastic-plastic-creep analysis is carried out.

\section{Failure evaluation}

According to the NEA reports (Nicolas, 2002), several failure evaluation criteria have been proposed as follows;

(1) "Considere" criterion

"Considere" criterion is a stress-based one. If the equivalent stress exceeds the threshold values of $\sigma_{\text {fail }}$, which is temperature dependent, the part is judged as failure. $\sigma_{\text {fail }}$ values are reported in the previous paper (Nicolas, 2002). In this study, damage variable based on the "considere" criterion, $D_{\text {cons }}$, is defined as Eq. (1).

$$
\mathrm{D}_{\text {cons }}(t)=\sigma_{e q}(T(t)) / \sigma_{\text {fail }}(T(t))
$$

\section{(2) Strain criterion}

This criterion is similar to "considere" criterion, but the factor used is equivalent strain, $\varepsilon_{\mathrm{eq}}$. If the $\varepsilon_{\mathrm{eq}}$ exceeds the predetermined strain value, $\varepsilon_{\text {fail }}$, the part is judged as failure. The damage variable based on the strain criterion, $D_{\text {strain}}$, is defined as following equation;

$$
D_{\text {strain }}(t)=\varepsilon_{e q}(T(t)) / \varepsilon_{\text {fail }}(T(t))
$$

where $\varepsilon_{\text {fail }}$ is set to be $120 \%$ in this study. This value is the same as that is described in the previous paper (Nicolas, 2002).

(3) Kachanov criterion

In an evaluation based on the Kachanov criterion, the damage variable due to creep damage, $D$, is defined as following equations;

$$
\begin{aligned}
& D=\int_{0}^{t} \dot{D}(t) d t \\
& \dot{D}(t)=\left\langle\frac{\sigma_{\text {Mises }}}{A(1-D)}\right\rangle^{R}
\end{aligned}
$$

where $\sigma_{\text {Mises }}$ is the Mises equivalent stress, $A$ and $R$ are material parameters with temperature dependent. $\dot{D}$ corresponds to the rate of damage variable $D$. When damage variable $D$ reaches one, the part is judged as failure. In this study, we do not take the variation of material properties such as Young's modulus and yield strength due to creep damage into account in order to simplify calculation routine and to reduce the calculation time. In the finite element analysis, integration of the damage variable is treated as Eqs. (5) and (6) considering time step of $\Delta t$ of increment $i$.

$$
\begin{aligned}
& \Delta D(\mathrm{t})=\left\langle\frac{\sigma_{e q}}{A(1-D)}\right\rangle^{R} \Delta t_{i} \\
& D\left(t_{i}\right)=D\left(t_{i-1}\right)+\Delta D\left(t_{i}\right)
\end{aligned}
$$


The parameters of $A$ and $R$ are redefined on the basis of experimental measurements as reported previous papers (Yamaguchi, 2014), (U.S.NRC, 1993). The parameters used in this study are listed in Table 1.

(4) Larson-Miller parameter criterion

Creep failure can be described on the basis of Larson-Miller parameter (LMP) as described following equation;

$$
L M P=T\left(C+\log t_{\mathrm{R}}\right)
$$

where $C$ is a material specific constant, $T$ is the temperature in Kelvin, and $t_{\mathrm{R}}$ is rupture time. In this study, $C$ is assumed to be 20 and LMP is determined based on the experimental results.

This equation is basically useful for the creep rupture under constant temperature and constant loading conditions. In other words, it is difficult to evaluate creep rupture by this equation when we consider complicated temperature and pressure distributions due to advances of the debris relocation. Therefore, we establish a creep damage evaluation method based on LMP as following;

a) A parameter $P$ related LMP is calculated by referring stress values evaluated by finite element analysis as described in Eq. (8).

$$
P\left(t_{R}, \mathrm{~T}\right)=\left[\log (\sigma)-c_{0}\right] / c_{1}
$$

where $c_{0}$ and $c_{1}$ are parameters determined from creep rupture time and multi-loading conditions.

b) Using calculated $P$, failure time $t_{\mathrm{R}}$ which corresponds to residual lifetime is calculated by Eq. (9).

$$
t_{R}=10^{\left[\mathrm{P}\left(t_{R}, T\right) / T-C\right]}
$$

c) Using residual lifetime (calculated in step 2) and increment time, $\Delta t_{i}$, variation of damage variable, $\Delta D_{\mathrm{LMP}, i}$, for each increment, $i$, is calculated by Eq. (10). And then, damage variable, $D\left(t_{\mathrm{i}}\right)$, for each increment is obtained by Eq. (11) as summation of $D\left(t_{\mathrm{i}-1}\right)$ and $\Delta D_{\mathrm{LMP}, i}$. If $\Delta D_{\mathrm{LMP}, i}$ value reaches one, such part is judged to be failure.

$$
\begin{aligned}
& \Delta D_{L M P, i}(t)=\Delta t_{i} / t_{R} \\
& D\left(t_{i}\right)=D\left(t_{i-1}\right)+\Delta D_{L M P, i}(t)
\end{aligned}
$$

Through this methodology, we can estimate the failure time based on the LMP even if the stress and temperature obtained from structural analysis show variation and complicated distribution. The parameters for LMP criteria used in this study are listed in Table 2. These parameters are determined by experimental measurements reported by separate papers (Yamaguchi, 2014), (U.S.NRC, 1993). 
Table 1 Kachanov parameters (Yamaguchi, 2014).

\begin{tabular}{c|c|c|c}
\hline \hline & Temperature $\left[{ }^{\circ} \mathrm{C}\right]$ & \multicolumn{2}{|c}{ Parameters of Kachanov model } \\
& & $A$ & $R$ \\
\hline \multirow{3}{*}{ SA533B } & $627^{*}$ & $3.81 \mathrm{e} 8$ & 4.04 \\
& $727^{*}$ & $2.22 \mathrm{e} 8$ & 1.86 \\
& $777^{*}$ & $7.95 \mathrm{e} 7$ & 4.14 \\
& $877^{*}$ & $6.15 \mathrm{e} 7$ & 3.45 \\
& 1000 & $4.83 \mathrm{e} 7$ & 3.23 \\
& 1200 & $1.14 \mathrm{e} 7$ & 4.27 \\
\hline
\end{tabular}

${ }^{*}$ The parameters are determined by fitting to experimental data in separate report (U.S.NRC, 1993)

Table 2 Coefficients for LMP criteria.

\begin{tabular}{c|c|c}
\hline \hline & $\boldsymbol{c}_{\boldsymbol{0}}$ & $\boldsymbol{c}_{\boldsymbol{1}}$ \\
\hline $\mathrm{SA533B}$ & 4.50 & $1.35 \times 10^{-4}$ \\
\hline
\end{tabular}

\section{Analysis models and methods}

To estimate time and location of rupture due to heating by molten pool (the relocated debris), coupled analysis of $\mathrm{TH}$ and structural analyses is performed. In this section, the methodology of the analysis is explained.

\subsection{Thermal-Hydraulics analysis}

The model used for TH analysis is shown in Fig. 1. The model is 1/4 model considering symmetry of lower head and configuration of control rod guide tubes. It is composed of tetra mesh and number of elements is 289,926. As shown in Fig. 2, boundary conditions for velocity and heat transfer are applied at surface of molten pool (a), interfaces between molten pool and lower head (b), molten pool and guide tube (c), molten pool and stub tubes (d), and surface of shroud support. Heat transfer coefficient and surface temperature at the initial stage are also shown in the figure. The pressure boundary of $1.0 \times 10^{6}[\mathrm{~Pa}]$ are also applied to the region of molten pool. Each material property is temperature dependent as listed in table 3 (U.S.NRC, 2000). To consider the phase transformation from solid to liquid, the specific heat between solidus and liquidus line temperatures $(2650[\mathrm{~K}]$ and $3123[\mathrm{~K}]$, respectively) is set as shown in Fig. 3.

In this study, we assumed that around $10 \%$ of reactor core is melted and relocated to vessel lower head and the coolant water in the reactor is completely evaporated (dried condition), and therefore, depth of the relocated debris is set to be $0.58[\mathrm{~m}]$ as shown in Fig. 4. Internal heat generation of $1.0 \times 10^{6}[\mathrm{~W} / \mathrm{m} 3]$ is taken into account. It should be noted that this scenario is different from that of $1 \mathrm{~F}$.

Temperature distribution at the surface of RPV, control rod guide tubes, and stub tubes calculated by the TH analysis is applied to structural analysis as boundary condition.

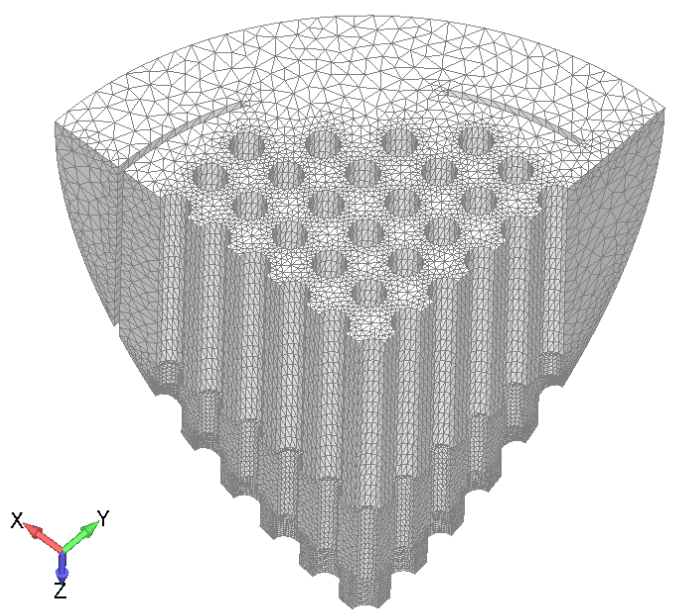

Fig. 1 Analysis model for TH analysis 


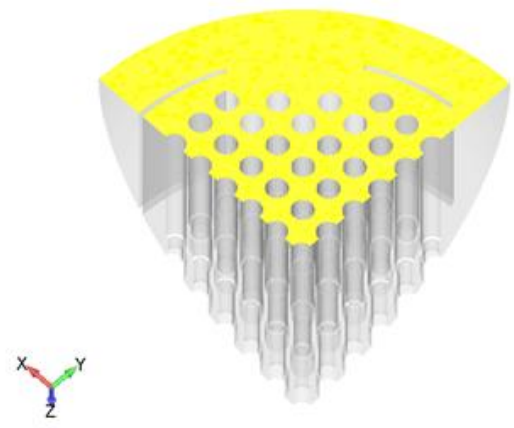

(a) Surface of molten pool $10\left[\mathrm{~W} / \mathrm{m}^{2} \mathrm{~K}\right], 300^{\circ} \mathrm{C}$

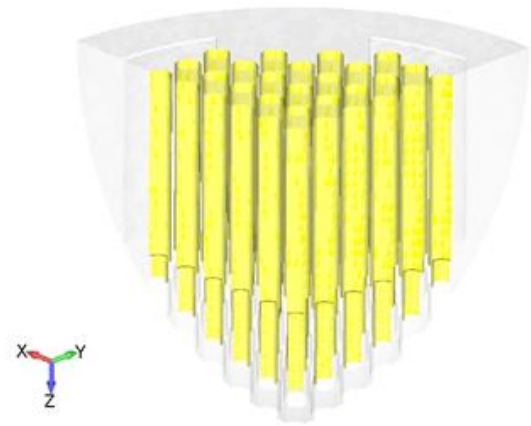

(c) Interface; pool / guide tubes $9.9\left[\mathrm{~W} / \mathrm{m}^{2} \mathrm{~K}\right], 300^{\circ} \mathrm{C}$

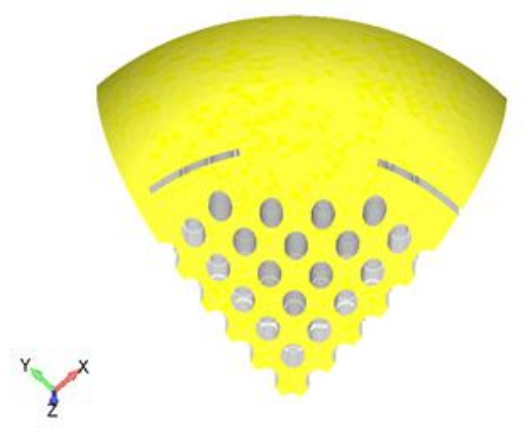

(b) Interface; pool / RPV $9.5\left[\mathrm{~W} / \mathrm{m}^{2} \mathrm{~K}\right], 20^{\circ} \mathrm{C}$

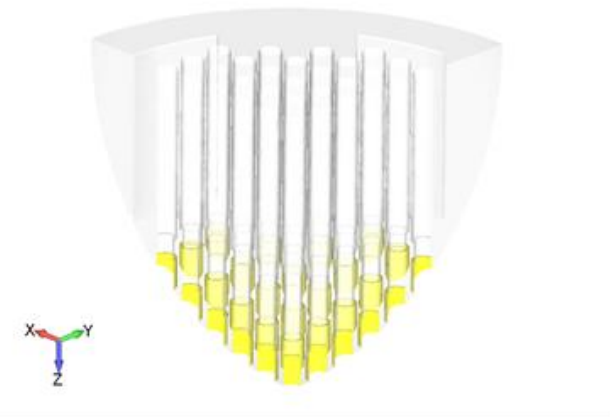

(d) Interface; pool / stub tubes

$9.7\left[\mathrm{~W} / \mathrm{m}^{2} \mathrm{~K}\right], 300^{\circ} \mathrm{C}$

Fig. 2 Boundaries for velocity and heat transfer at the initial stage

Table 3 Material properties for TH analysis.

\begin{tabular}{cc}
\hline \hline Density $\left[\mathrm{kg} / \mathrm{m}^{3}\right]$ & 9200.0 \\
\hline Viscosity $[\mathrm{kg} /(\mathrm{m} \cdot \mathrm{s})]$ & $1.0 \times 10^{6}(\mathrm{~T}<2650[\mathrm{~K}])$ \\
& $0.0045(\mathrm{~T}>3123[\mathrm{~K}])$ \\
\hline Heat transfer coefficient $[\mathrm{W} /(\mathrm{m} \cdot \mathrm{K})]$ & 8.0 \\
\hline Specific heat $[\mathrm{J} /(\mathrm{Kg} \cdot \mathrm{K})]$ & $400(\mathrm{~T}<2650[\mathrm{~K}])$ \\
& $2013(\mathrm{~T}=2887[\mathrm{~K}])^{*}$ \\
& $650(\mathrm{~T}>3123[\mathrm{~K}])$ \\
\hline Thermal expansion $[1 / \mathrm{K}]$ & $($ See Fig. 3; 2650 3123 [K]) \\
\hline
\end{tabular}

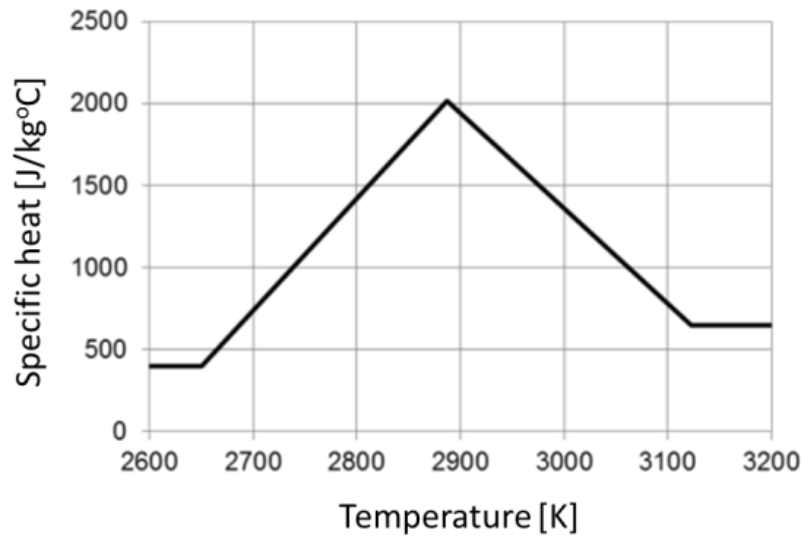

Fig. 3 Temperature dependency of specific heat during transformation from solid to liquid 


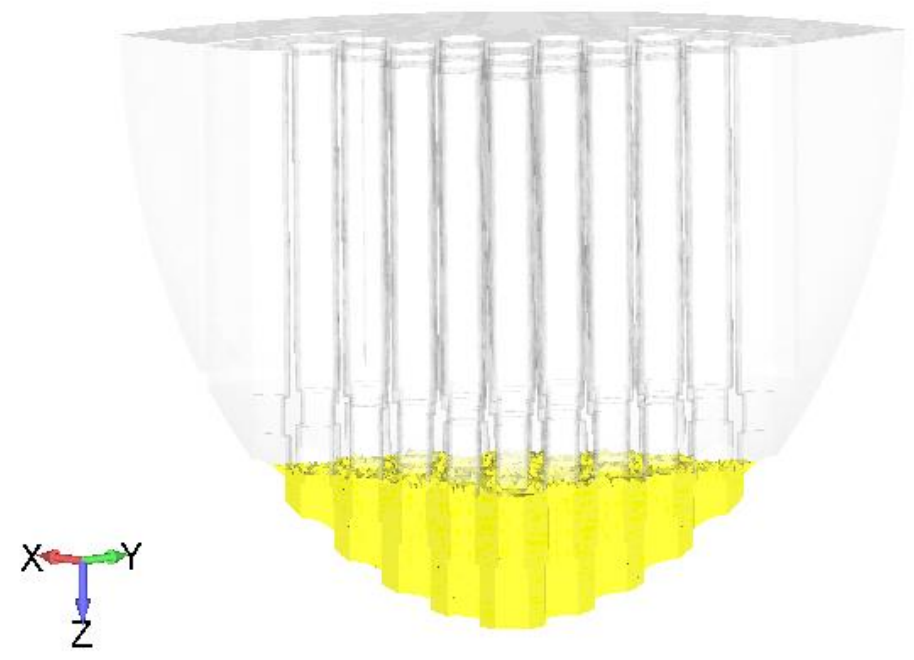

Fig. 4 Assumed region for relocated debris

\subsection{Structural analysis and creep damage evaluation}

According to several published papers (For example, U.S.NRC, 2002), we establish three-dimensional model of RPV lower head including control-rod penetrations, stub tubes, J-groove welds, weld-overlay cladding, shroud support, and skirt of RPV as shown in Fig. 5. Number of elements is 113,877. The materials used in the model are lower alloys steel (ASTM A533B; RPV, skirt), austenitic stainless steel (Type 316 stainless steel; control rod guide tube, cladding, shroud support), and nickel based alloy (Alloy 600; stub tube, J-groove weld). Each material property of Young's modulus, Poisson's ratio, yield strength, hardening coefficient after yielding, creep constitutive law is temperature dependent.

Surface temperature obtained from $\mathrm{TH}$ analysis is applied to this structural analysis on the basis of elastic-plastic-creep analysis as described previously. Creep damage evaluations based on "considere", strain, Kachanov, and LMP criteria are performed by using calculated stress or strain values.

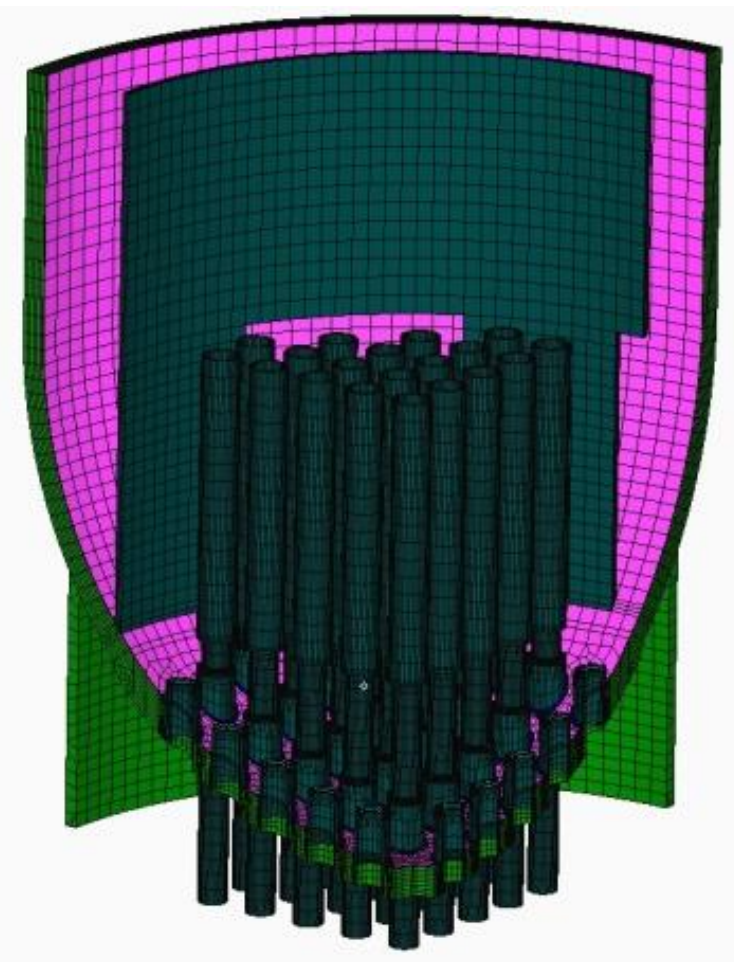

(a) Aspect of analysis model for structural and creep damage evaluation (Color: material separation)

Fig. 5 Analysis model for structural analysis 


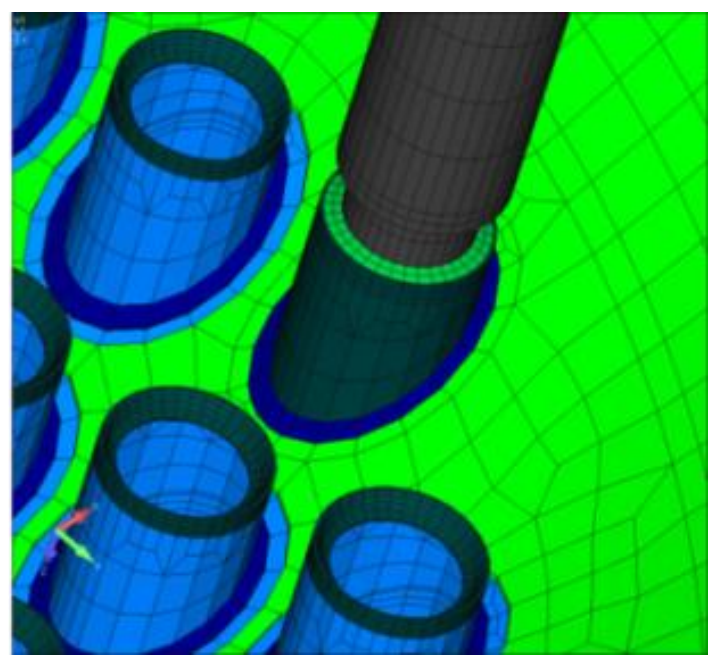

(b) Close-up view of welds

Fig. 5 Analysis model for structural analysis (cont'd)

\section{Results and discussion}

\subsection{Thermal hydraulics analysis}

To confirm the applicability of FINAS/CFD to analysis of melting behavior of metals, we compared the analysis results to previous one (Sampath, 1999). The material used in this analysis is Gallium which melting point is 29.8 [ ${ }^{\circ} \mathrm{C}$ ] (303.0 $[\mathrm{K}])$. Specific heat during phase transformation is considered as described previously. Temperature boundary conditions of $311.45[\mathrm{~K}]$ and $302.93[\mathrm{~K}]$ are applied to left and right edges of analysis model, respectively. The gravity acceleration of $9.80665[\mathrm{~m} / \mathrm{s} 2]$ is considered as well. Figure 6 represents a comparison in temperature distribution between analysis and experiment. Temperature distribution is represented by normalizing as $\hat{T}=\left(T-T_{1}\right) /\left(T_{2}-T_{1}\right)$ (where $T_{1}$ and $T_{2}$ are 302.93 and 311.45 , respectively) in order to compare the analysis results to previous one (Sampath, 1999). Temperature distribution obtained from FINAS/CFD agreed well with previous analysis result. We also confirmed that flow rate distribution evaluated by FINAS/CFD showed good agreement with previous one. From these facts, we could confirm that FINAS/CFD has a sufficient accuracy to analyze the melting behavior of metals.

Typical analysis results of temperature distributions at lower head due to heating of the relocated debris are shown in Fig. 7. The time shown in the figure corresponds to the elapsed time from the beginning of internal heating because of evaporation of the coolant water. The maximum temperature is located near the center and upper region of the debris, it reaches melting point of debris $(\sim 2650[\mathrm{~K}])$ after around 9000 [sec]. It is noted that convection flow is locally recognized in the molten region. From these facts, it is concluded that the melting behavior of the debris can be simulated by taking the phase transformation into account by FINAS/CFD. 


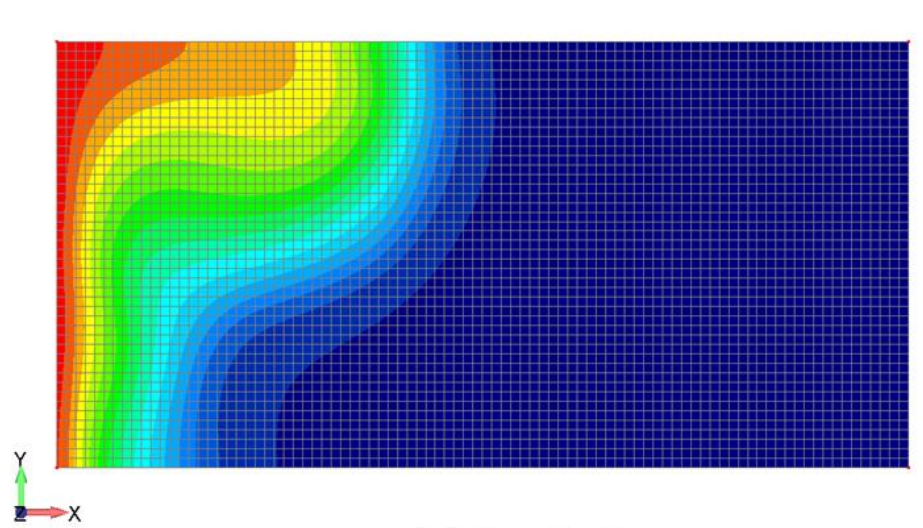

(a) Analysis
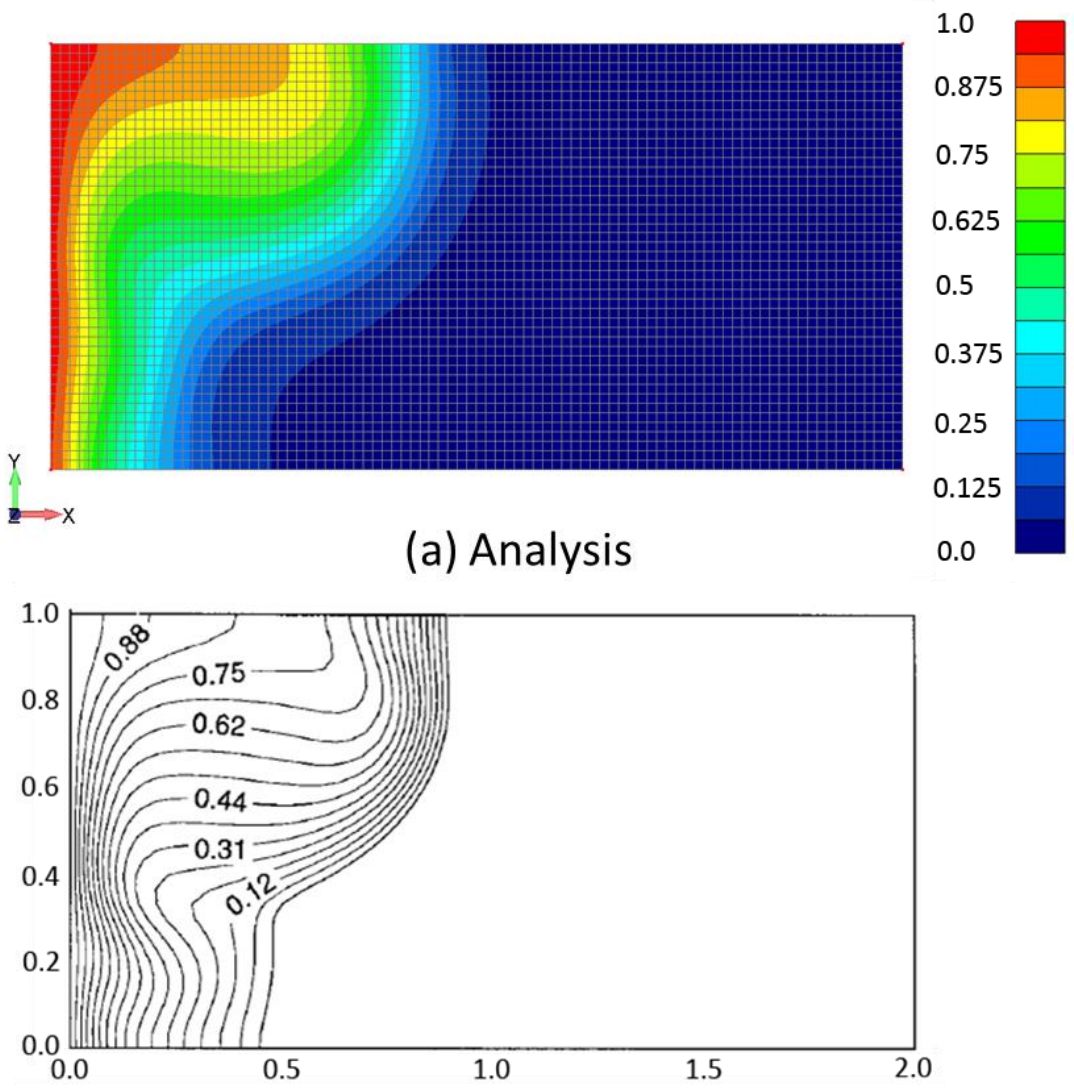

(b) Experiment

(b) Closeup view of welds

Fig. 6 Comparison in temperature distributions between analysis and experiment (at 8 [min])
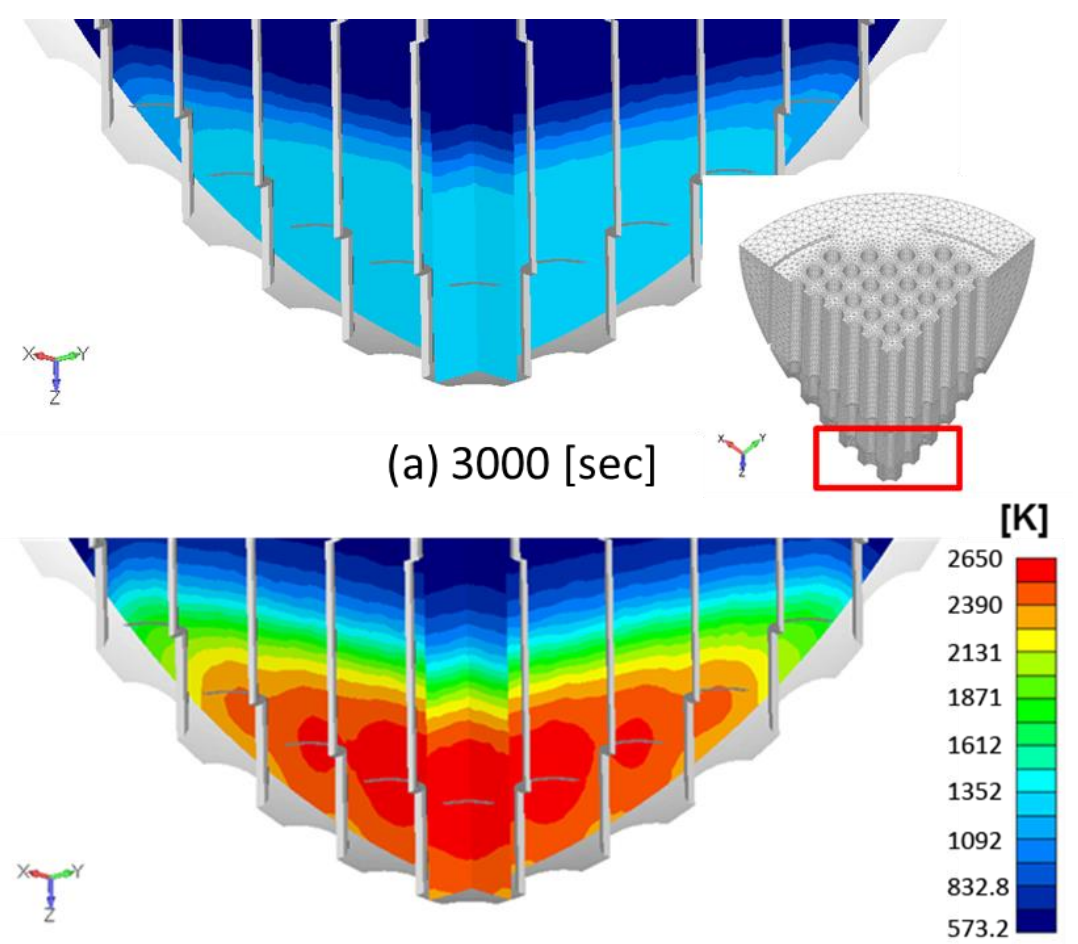

(b) $9000[\mathrm{sec}]$

Fig. 7 Temperature distribution at lower head 


\subsection{Structural analysis and creep damage evaluation}

As described previously, the structural analysis based on elastic-plastic-creep analysis using FINAS/STAR is carried out by applying the temperature distributions at the surface of RPV, guide tubes, and stub tubes calculated by TH analysis. The results obtained from the analysis are shown in Fig. 8. As shown in Fig. 8 (a), temperature distribution calculated by $\mathrm{TH}$ analysis is correctly mapped to structural analysis model, e.g. a region where the maximum temperature is indicated agree with that of TH analysis. As shown in Fig. 8 (b), Mises stress near the center of lower head becomes low because of decreasing of yield strength due to heating. In contrast, higher Mises stresses drawn by red or green are recognized at outward of lower head where roughly corresponds to the surface of heated area (see Fig. 4). These tendencies of Mises stress distributions are similar to the previous papers which focused on rupture analysis for lower head of reactors (Onizawa, 1993), (Humphphries, 2002), (Villanueva, 2011). In our analysis case, it is noted that the highest Mises stresses occur within the penetrations at outward of lower head. This fact means that, when we estimate failure behaviors of lower head of BWR due to severe accident, geometrically complicated models including penetrations should be used for failure evaluation.

Figures 9 to 11 represent preliminary analysis results based on "considere", Kachanov, and LMP criteria, respectively. These figures show the results at the moment when at least one element is judged to be failure. The location where is judged as rupture is shown by dotted circle(s). Contours for only RPV are drawn since damage evaluations were performed for only RPV steel in this study because of the limitation of experimentally obtained parameters. Although results from strain criterion are not shown here, there are no regions where are judged to be rupture based on strain criterion.

From "considere" and Kachanov criteria, it is shown that some locations near the penetrations at the outer surface of RPV are judged as rupture at around 600 [sec] (Fig. 9) and 1,000 [sec] (Fig. 10), respectively. LMP criterion provides different result from "considere" and Kachanov criteria, i.e. rupture occurs near the penetrations at the inner surface of RPV. Failure time evaluated by Kachanov and LMP criteria are 1,200 [sec]. It is considered that the difference in failure time between Kachanov and LMP criteria might be small because creep behavior intrinsically includes large scatter in elongation and/or rupture time.

The results obtained from each damage criterion are summarized in table 4. It is noted that each criterion indicates that rupture of reactor due to heating by the relocated debris occurs at similar location, i.e. the control rod guide tube penetrations, and the results are obviously different from the Mises stress distribution shown in Fig. 8 (b). In addition, there is a large difference in failure time as shown in table 4. Further improvements of evaluation methods are necessary for more accurate assessments of rupture behavior of RPV.

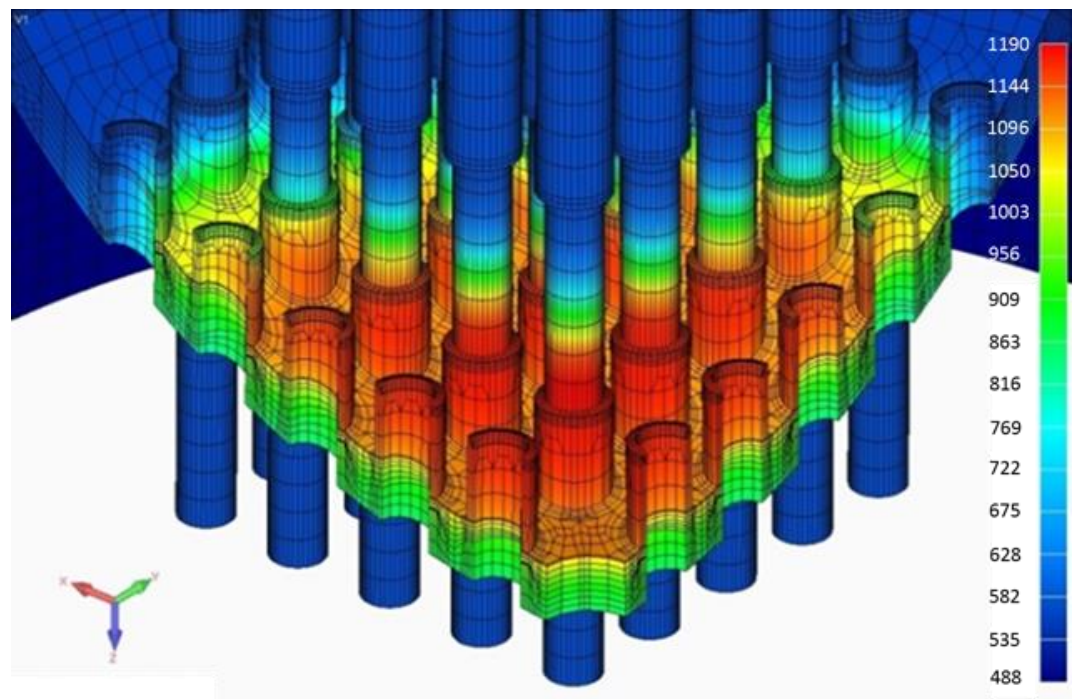

(a) Temperature

Fig. 8 Temperature (a) and Mises-equivalent stress (b) distributions at lower head (at 2,000 [sec]) 
Katsuyama, Yamaguchi, Nemoto, Kaji and Yoshida, Mechanical Engineering Journal, Vol.3, No.3 (2016)

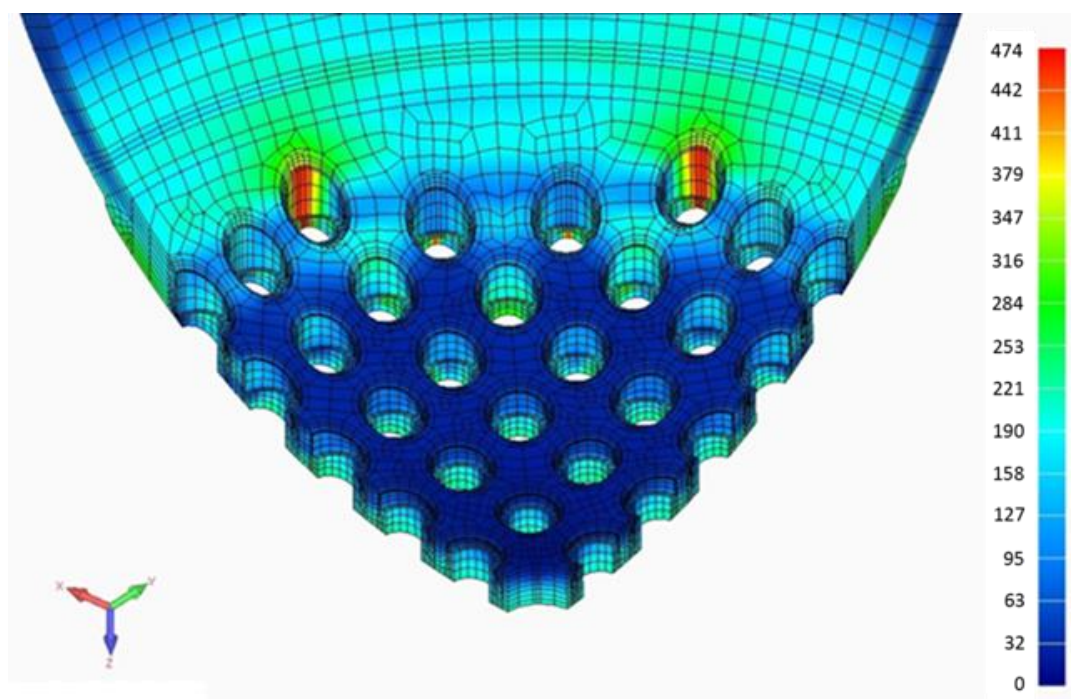

(b) Mises equivalent stress

Fig. 8 Temperature (a) and Mises-equivalent stress (b) distributions at lower head (at 2,000 [sec]) (cont'd)
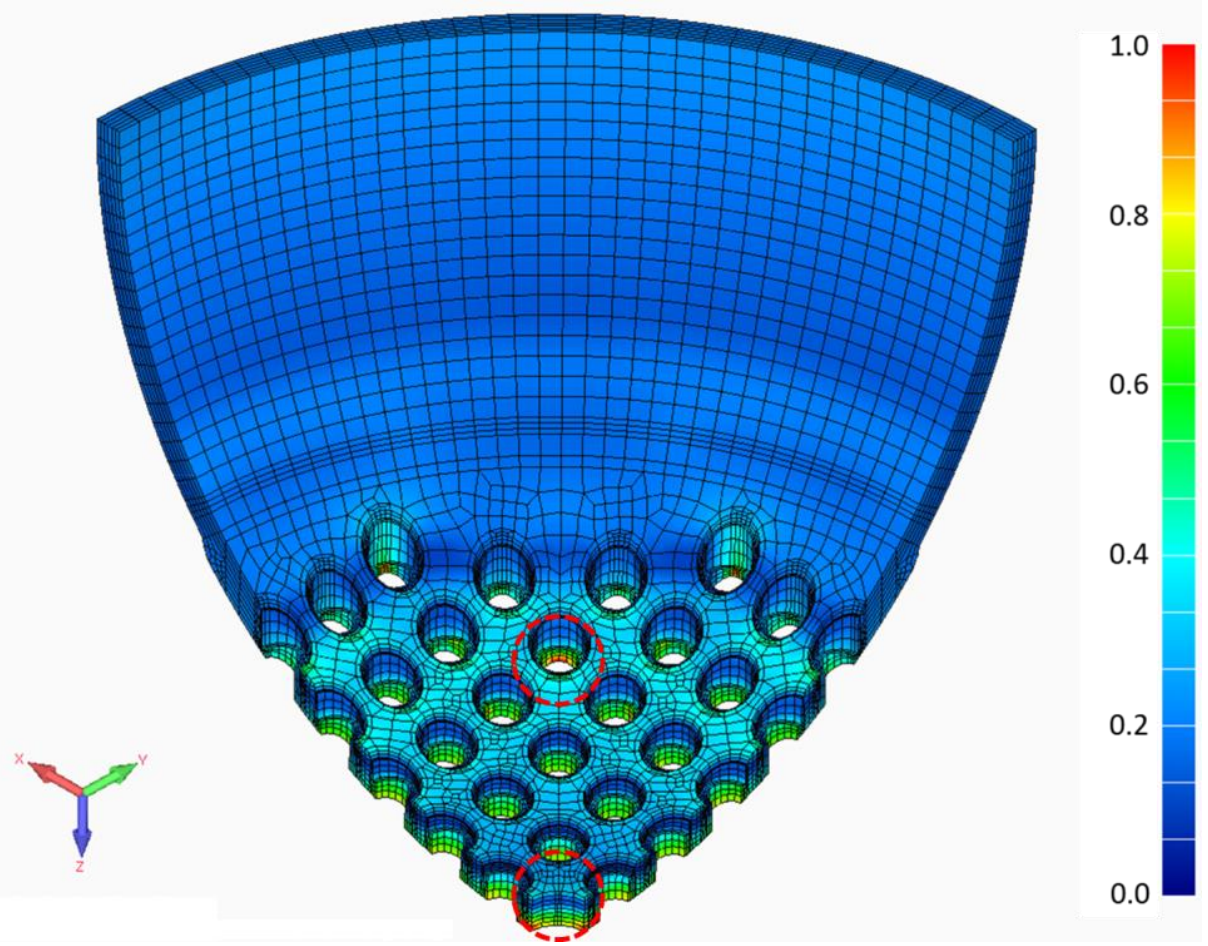

Fig. 9 Damage distribution from "considere" criterion at lower head (at 600 [sec]) 

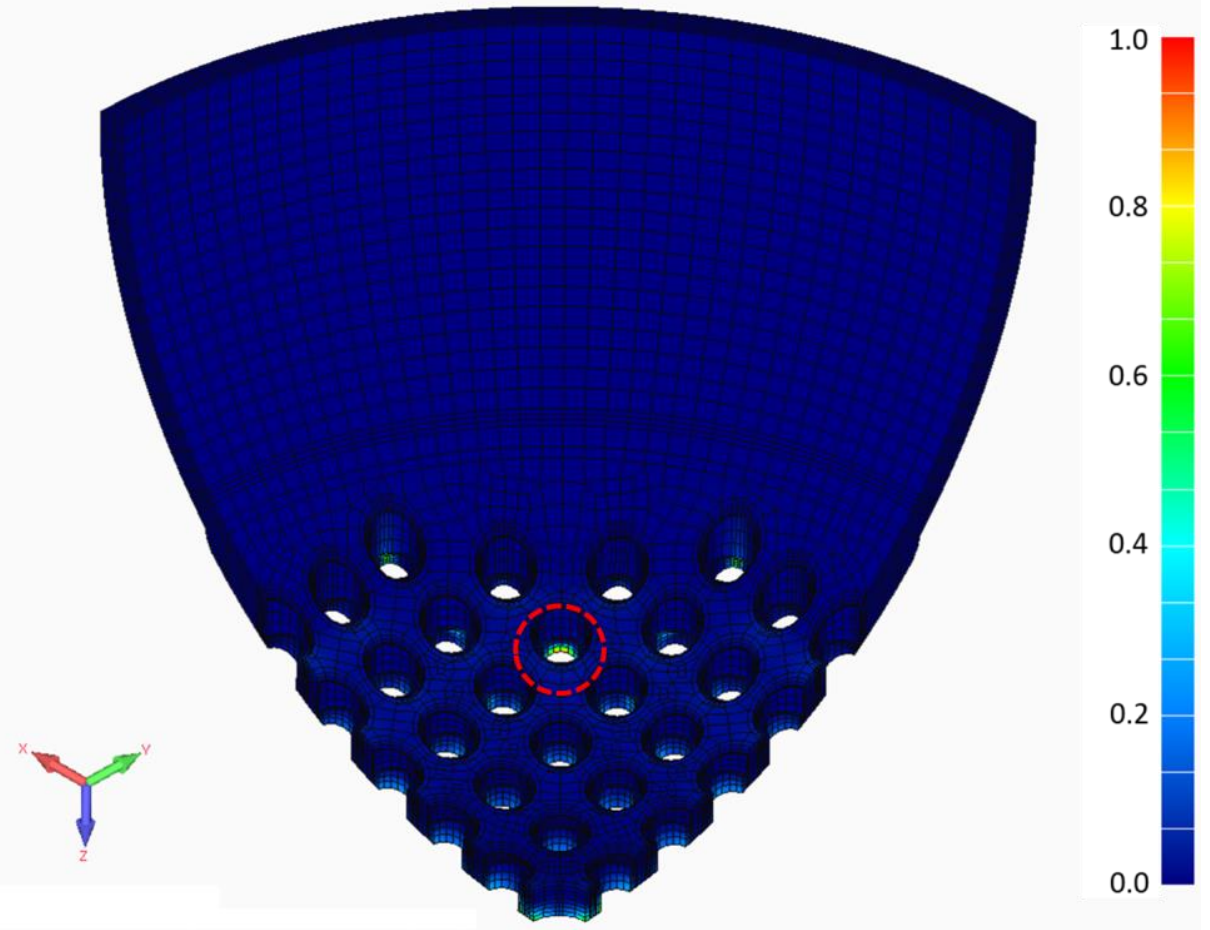

Fig. 10 Damage distribution from Kachanov criterion at lower head (at 1000 [sec])
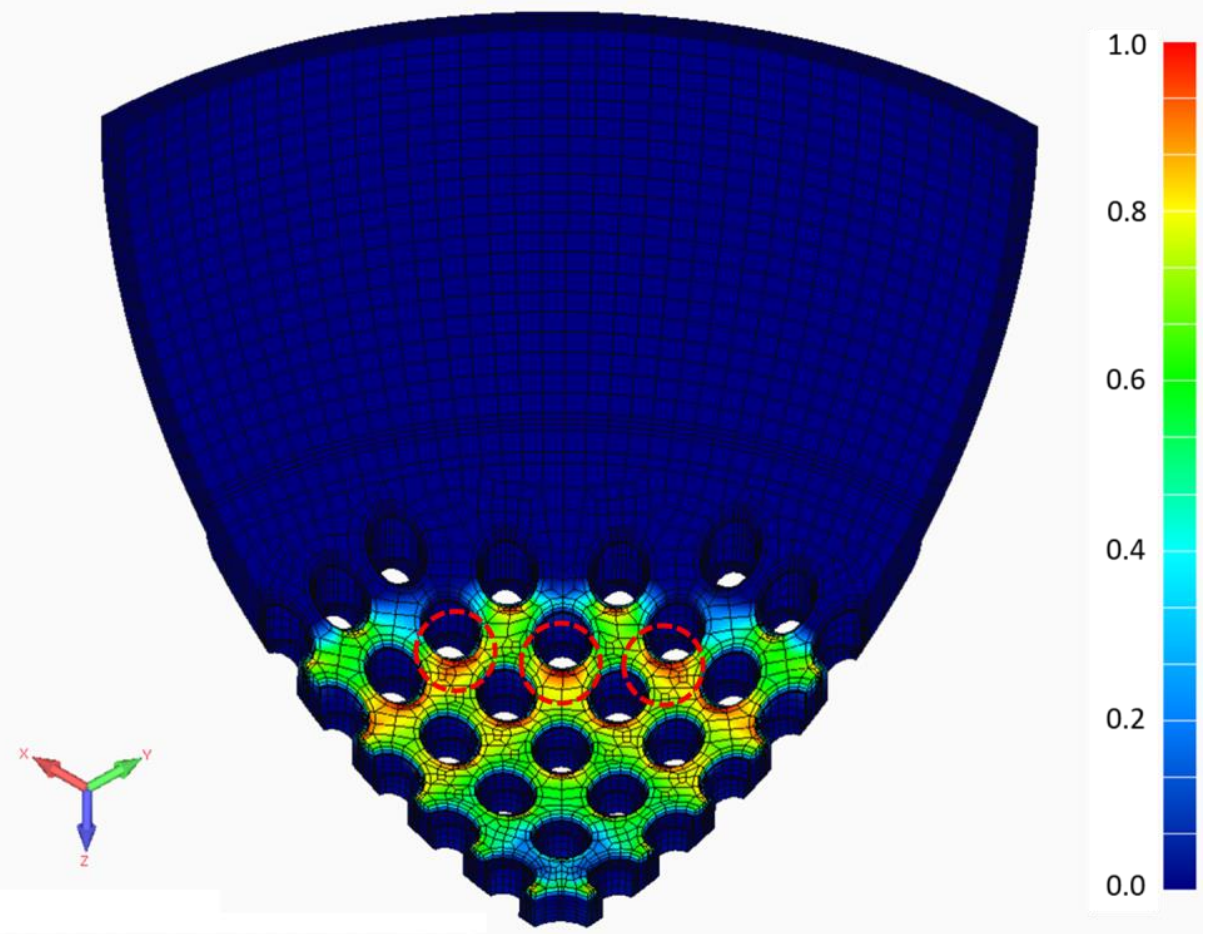

Fig. 11 Damage distribution from LMP criterion at lower head (at 1300 [sec]) 
Table 4 Damage evaluation results.

\begin{tabular}{ccccc}
\hline \hline Failure criterion & $\begin{array}{c}\text { “Considere” } \\
\text { criterion }\end{array}$ & $\begin{array}{c}\text { Strain criterion } \\
\mathbf{( 1 2 0 \% )}\end{array}$ & $\begin{array}{c}\text { Kachanov } \\
\text { Damage criterion }\end{array}$ & LMP criterion \\
\hline Failure time [sec] & 600 & - & 1,000 & 1,200 \\
\hline $\begin{array}{c}\text { Location of } \\
\text { failure }\end{array}$ & $\begin{array}{c}\text { Penetrations } \\
\text { Outer surface }\end{array}$ & - & $\begin{array}{c}\text { Penetrations } \\
\text { Outer surface }\end{array}$ & $\begin{array}{c}\text { Penetrations } \\
\text { Inner surface }\end{array}$ \\
\hline
\end{tabular}

\section{Summary}

To assess progress of severe accident and to predict time and location of rupture of reactors due to severe accident, we developed finite element model of RPV lower head including penetrations and welds, and four types of creep damage failure evaluation methods of "considere", strain, Kachanov, and LMP criterions. Through coupled analysis of TH and structural analyses, it was shown that failure regions of BWR lower head are only penetrations under simulated conditions.

\section{References}

Humphphries L. L. et al., OECD Lower Head Failure Project Final Report (Volume 1 - Integral Experiments and Material Characterization) (2002).

Humphphries L. L. and Smith J., OECD Lower Head Failure Project Final Report (Volume 2 - Numerical Simulation and Modeling) (2002).

ITOCHU Techno-Solutions Corporation, FINAS/CFD theoretical manual, Ver. 2013 (2013). (in Japanese)

ITOCHU Techno-Solutions Corporation, FINAS/STAR theoretical manual, Ver. 2013 (2013). (in Japanese)

Nicolas L. and Locatelli T., Failure propagation simulation in a RPV lower head under severe accident loading conditions, OLHF Seminar, Madrid June 2002 (2002).

Onizawa K. and Hashimoto K., Three-dimensional thermal stress analyses for the TMI-2 vessel lower head using finite element method, Three mile island reactor pressure vessel investigation project, achievements and significant results (1993), pp. 322-334.

Sampath R. and Zabaras N., An objective oriented implementation of a front tracking finite element method for directional solidification processes, International Journal for Numerical Methods in Engineering, Vol 44 (1999), pp. 1227-1265.

Tran C. T., Kudinov P. and Dinh T. N., An approach to numerical simulation and analysis of molten corium coolability in a boiling water reactor lower head, Nuclear Engineering and Design, Vol. 240 (2010), pp. 2148-2159.

U.S.NRC, "Light Water Reactor Lower Head Failure Analysis," NUREG/CR-5642 (1993).

U.S.NRC, Material Properties Package Reference Manual, MELCORE Computer Code Manuals, NUREG/CR-6119 (2000).

U.S.NRC, Special Consideration for BWR Facilities, NUREG/CR-6042. Rev. 2 (2002).

Villanueva W., Tran C. T. and Kudinov P., Coupled thermo-mechanical creep analysis for boiling water reactor pressure vessel lower head, Nuclear Engineering and Design, Vol. 249 (2011), pp. 146-153.

Yamaguchi Y., Katsuyama J., Kaji Y., Yoshida H., and Li Y., Development of Failure Evaluation for BWR Lower Head in Severe Accident; (1) High Temperature Creep Test and Creep Damage Model, Proceedings of ICONE-23, ICONE23-1533 (2015). 